\title{
The Preservation of Erythrocytes at Liquid Nitrogen Temperatures with Hydroxyethyl Starch: the Removal of Hydroxyethyl Starch from Erythrocytes after Thawing
}

\author{
C. T. KNORPP, W. H. STARKWEATHER, H. H. SPENCER, AND \\ L. WEATHERBEE
}

\section{U.S. Veterans Administration Hospital, Medical Research and Departments of Medicine, and Pathology, University of Michigan Medical Center, Ann Arbor, Michigan 48105}

Hydroxyethyl starch (HES) has been shown to protect erythrocytes from freeze-thaw damage when these cells are frozen rapidly in liquid nitrogen and stored in the vapor phase at $145^{\circ} \mathrm{C}(8,14)$. This alkylated starch is a product of the reaction of ethylene oxide and amylopectin (7). The viscosity and molecular weight of the material is adjusted by acid hydrolysis. The product used in this study has a weight average molecular weight (MW) of 120,000 and a weight number molecular weight (MN) of $41,000 .{ }^{1}$ The large discrepancy between these two figures is explained by the definition of the two terms; the MW describes average particle weight while MN refers to the number of molecules present. The ratio of the two describes the heterogeneity of the polymer.

Because of the high viscosity of erythrocyte-HES mixture, administration to patients is relatively slow. Therefore, washing the cells aftor thawing appears to be advantageous if such rells are to be more rapidly available for routine clinical use. In our experience, the transfusion of a full unit of frozen thawed erythrocytes, containing $75 \mathrm{gm}$ of HES, to patients produced no adverse effects. However, lowering the viscosity by removal of all or part of the HES after thawing would allow more rapid administration of the product. This paper will describe a method for washing red blood cells that appears promising. To assess the effectiveness of the freeze-thaw cycle, red blood cell saline stability, total red cell recovery, and supernatant hemoglobin levels were determined prior to freezing, after thawing, and after the final wash. In len of the samples $\mathrm{K}^{+}$and ATP levels were also determined.

Received April 25, 1971.

${ }^{1}$ The HES was obtained from McGaw Laboratories. Division of American Hospital Supply Corporation, Glendalc, CA 91201.

\section{METHODS}

Blood was obtained from donors using $\mathrm{ACD}-\mathrm{A}$ as an anti-coagulant in polyvinyl chloride bags. In some instances, blood bank blood was used instead of fresh donor blood. The blood was centrifuged at $1500 \mathrm{~g}$ to pack the erythrocytes. The plasma was removed, and the cells were washed three times with equal volumes of $0.154 \mathrm{~N} \mathrm{NaCl}$. After the last wash the packed cells were suspended in a mixture of $\mathrm{NaCl}$ and HES so that the final concentration of HES was $14 \%$.

A $30 \mathrm{ml}$ aliquot of blood-HES mixture was placed in a $9 \mathrm{~cm}^{2}$ plastic bag (Hemoflex TM) . This plastic is $3 / 1000$ of an inch thick. After sealing the bag it was inserted in an outer envelope of Hemoflex $\left(11 \mathrm{~cm}^{2} \times 3 / 1000\right.$ in thick $)$ and placed in a rubberized spring loaded holder (Fig. 1). The holder was then immersed in liquid nitrogen and agitated at $160 \mathrm{cpm}$ using a BP-2 Blood Processing Machine. This system was designed by the Linde Division of the Union Carbide Corporation, and consists of a compressed air actuated arm driven by a wrist action shaker. The frozen blood-HES mixture was removed from the holder and stored at $-145^{\circ} \mathrm{C}$.

Prior to thawing, the outer bag was removed and the inner bag containing the frozen blood was then placed in the rubberized holder, and agitated by the machine at 160 cycles per minute for $40 \mathrm{sec}$ in a $47^{\circ} \mathrm{C}$ circulating watcr bath. The final temperature of the blood was $20^{\circ} \mathrm{C}$.

Postthaw parameters included the following determinations: hematocrit, supernatant hemoglobin (15), the stability of the cells in $0.154 \mathrm{~N}$ $\mathrm{NaCl}$ (13), and the immediate postthaw recovery of the intact erythrocytes (8). The saline

${ }^{2}$ Hemoflex TM obtained from Union Carbide Corporation, Films Packaging Division, 6733 West 65th Street, Chicago IL 60638. 


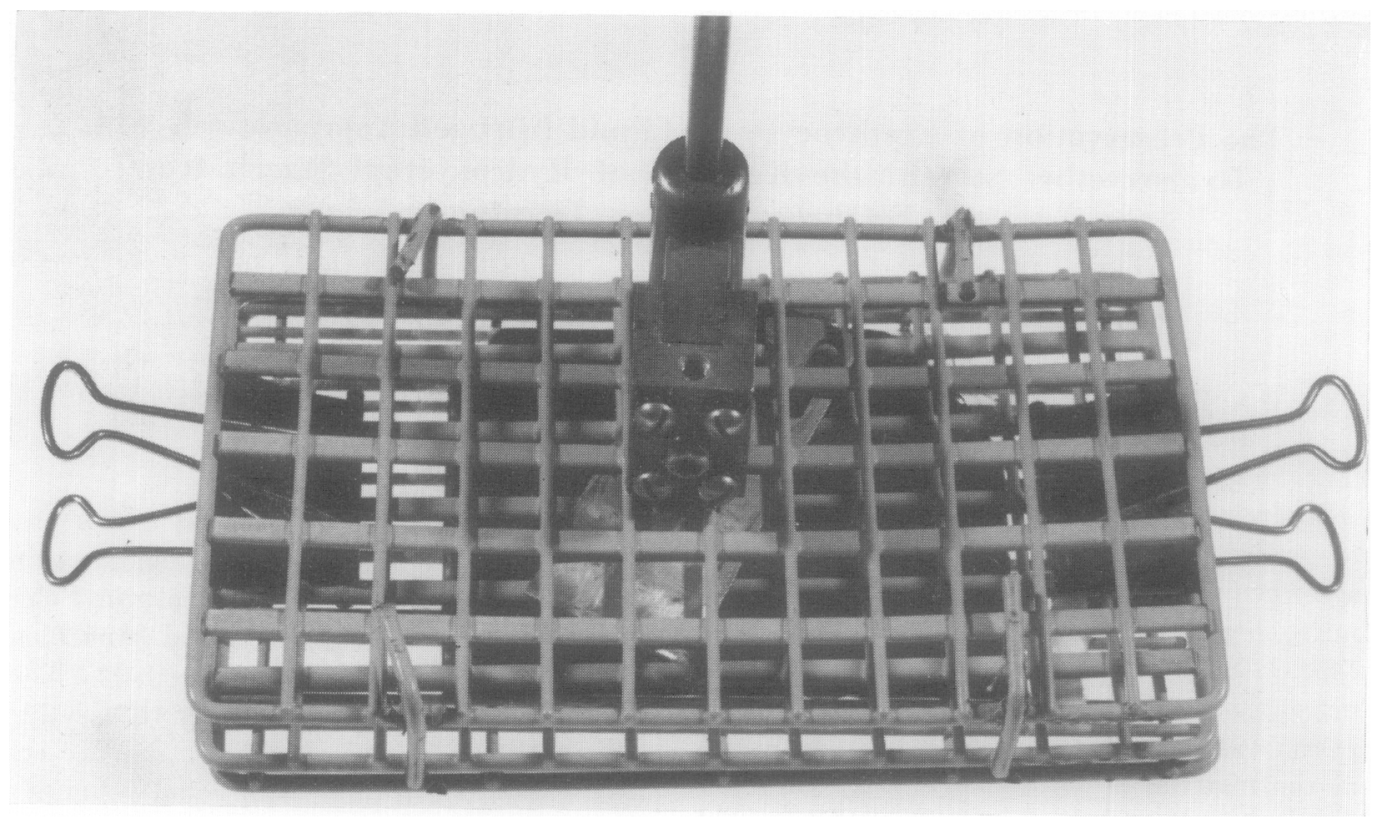

FIG. 1. Rubberized spring loaded holder containing a $30 \mathrm{ml}$ aliquot of blood-HES mixture placed in a $9 \mathrm{~cm}$ plastic bag.

stability was determined in the following manner: A small volume of thawed blood $(0.4 \mathrm{ml})$ was diluted 1:40 with $0.154 \mathrm{~N} \mathrm{NaCl}$. Two milliliters of this suspension were lysed in $8 \mathrm{ml}$ of $0.1 \% \mathrm{Na}_{2} \mathrm{CO}_{3}$. After $30 \mathrm{~min}$, the saline suspension was centrifuged and the hemoglobin level was determined on the supernatant and compared to the completely lysed suspension to determine the percentage of stable cells as calculated in the following equation:

$$
\frac{\mathrm{Hgb}(\mathrm{NaCl}) \times 40}{\mathrm{Hgb}\left(\mathrm{Na}_{2} \mathrm{CO}_{3}\right) \times 200} \times 100
$$

The percentage of cells recovered immediately postthaw was determined by lysing $0.1 \mathrm{ml}$ of blood in $19.9 \mathrm{ml}$ of $0.1 \% \mathrm{Na}_{2} \mathrm{CO}_{\mathrm{B}}$. A whole blood sample was then centrifuged, and $0.5 \mathrm{ml}$ of plasma was added to $9.5 \mathrm{ml}$ of $0.1 \% \quad \mathrm{Na}_{2} \mathrm{CO}_{3}$. The plasma hemuglobin was compared to the total hemoglobin and recovery was calculated thus:

$$
100-\frac{\text { Plasma Hgb } \times 20}{\text { Total } \mathrm{Hgb} \times 200} \times 100-\mathrm{HCT}
$$

The final recovery of washed blood was calculated from the total amount of hemoglobin contained in the mixture prior to washing, and the amount of hemoglobin recovered in the washes as expressed in the next equation.

$$
\frac{(\text { Total } \mathrm{Hgb})-\mathrm{Hgb} \text { in wash }}{\text { Total Hgb }} \times 100
$$

The hemoglobin levels used to calculate recovery and saline stability were determined with a Coleman Jr. spectropholomeler at $540 \mathrm{~nm}$. Supernatant hemoglobin levels after thawing were determined as described by Shinowara (15) using a double beam Hitachi-Perkin Elmer recording spectrophotometer. The absorbancy at 575 and $560 \mathrm{~nm}$ were compared to determine the supernatant hemoglobin content of washed cells. If the cells were not washed an extra reading at 450 nm was added to correct for bilirubin content (15)

After thawing, a $5 \mathrm{ml}$ aliquot of packed cells was suspended in $10 \mathrm{ml}$ of Normasol-R. This is a balanced solution containing $9 \times 10^{-3} \mathrm{M} \mathrm{NaCl}$, $2.7 \times 10^{-3} \mathrm{M}$ sodium acetate, $2.3 \times 10^{-3} \mathrm{M}$ sodium gluconate, $5 \times 10^{-4} \mathrm{M}$ potassium chloride, and $1.5 \times 10^{-4} \mathrm{M}$ magnesium chloride. The $\mathrm{pH}$ is adjusted to 7.4 by the addition of $\mathrm{HCl}$ to a final concentration of $1 \times 10^{-3} \mathrm{M}$. The cell suspension was then centrifuged for $10 \mathrm{~min}$ at $2,000 \mathrm{~g}$. The supernatant was removed and saved, and the 
cells were washed four additional times with 10 $\mathrm{ml}$ of Normasol-R. The hemoglobin content of the pooled washes was determined to calculate the total recovery of erythrocytes after processing.

The effect of freezing, thawing and washing erythrocytes in the presence of HES, upon intracellular potassium and ATP levels was determined using methods described by Boutwell (2) and Beutler (1). The stability of ATP during a three hour incubation in Krebs-Ringer Phosphate was also evaluated.

\section{RESULTS}

Table 1 shows results abtained from 48 samples of thawed and washed blood. The plasma hemoglobin ranged from $177 \mathrm{mg} / 100 \mathrm{ml}$ to 820 $\mathrm{mg} / 100 \mathrm{ml}$, but only nine of these aliquots had hemoglobin levels in excess of $500 \mathrm{mg} / 100 \mathrm{ml}$. The postthaw recoveries ranged from 96 to $99 \%$ and the saline stability from 77 to $89 \%$. The postwash recoveries ranged from 76 to $91 \%$ closely approximating the saline stability of the red cells obtained immediately postthaw. The supernatant hemoglobin following the last wash ranged from 20 to $57 \% \mathrm{mg}$. Sixteen of the 48 blood samples were 5-21 days old. These units all demonstrated high plasma hemoglobins after thawing, and had saline stabilities less than $80 \%$. (It should be noted that in our experience with polyvinylpyrolidone (PVP) as the cryoprotective agent, bank blood over 5 days old did not tolerate the freeze process well). This observation has also been made by other investigators who have frozen erythrocytes protected by glycerol techniques. Tables 2 and 3 compare the data obtained with the samples whose saline stability was above $80 \%$ and those aliquots which fell below $80 \%$. The overall recovery immediately postthaw and after the washing process was significantly greater among the group with the high stability than those with a lower saline

TABLE 1

Postthaw Values For All Samples Processed

\begin{tabular}{lccc} 
& \multicolumn{1}{c}{ Mean } & Standard deviation & Number of samples \\
\hline Post thaw plasma Hgb & $405 \mathrm{mg} / 100 \mathrm{ml}$ & $168 \mathrm{mg} / 100 \mathrm{ml}$ & 48 \\
Saline stability & $82 \%$ & $4.12 \%$ & $4 \times$ \\
Post thaw recovery & $98 \%$ & $0.85 \%$ & $4 \times$ \\
Postwash recovery & $83.5 \%$ & $4.4 \%$ & 48 \\
Postwash Hgb & $33.9 \mathrm{mg} / 100 \mathrm{ml}$ & $10.6 \mathrm{mg} / 100 \mathrm{ml}$ & 48 \\
\hline
\end{tabular}

TABLE 2

PostThaw Values For Samples With Saline Stabilities Greater Than $80 \%$

\begin{tabular}{llcc} 
& \multicolumn{1}{c}{ Mean } & Standard dcviation & Number of samples \\
\hline Post thaw plasma Hgb & $324 \mathrm{mg} / 100 \mathrm{ml}$ & $67 \mathrm{mg} / 100 \mathrm{ml}$ & 32 \\
Saline stability & $85 \%$ & $2.2 \%$ & 32 \\
Postthaw recovery & $98.3 \%$ & $0.5 \%$ & 32 \\
Postwash recovery & $85.7 \%$ & $2.7 \%$ & 32 \\
Postwash Hgb & $35.9 \mathrm{mg} / 100 \mathrm{ml}$ & $10.9 \mathrm{mg} / 100 \mathrm{ml}$ & 32 \\
\hline
\end{tabular}

TABLE 3

Postrhaw Values For Samples With Saline Stabilities Less Than $80 \%$

\begin{tabular}{lccc}
\hline & \multicolumn{1}{c}{ Mean } & Standard deviation & Number of samples \\
\hline Postshaw plasma Hgb & $553 \mathrm{mg} / 100 \mathrm{ml}$ & $188 \mathrm{mg} / 100 \mathrm{ml}$ & 16 \\
Saline stability & $77.4^{\%}$ & $1.5 \%$ & 16 \\
Postthaw recovery & $97.1 \%$ & $0.86 \%$ & 16 \\
Postwash recovery & $78.9 \%$ & $3.5 \%$ & 16 \\
Postwash Hgb & $29.9 \mathrm{mg} / 100 \mathrm{ml}$ & $8.8 \mathrm{mg} / 100 \mathrm{ml}$ & 16 \\
\hline
\end{tabular}


stability. The plasma hemoglobins determined immediately after thawing were considerably lower, ranging from 177 to $325 \mathrm{mg} / 100 \mathrm{ml}$ in the units with higher saline stabilities.

Table 4 shows the recovery and saline stability of cells before and after washing. The recovery as calculated from loss of hemoglobin during wash, compares closely to the saline stability of these cells prior to wash. The washed cells demonstrate saline stabilities in excess of $96 \%$ possibly suggesting a stable cell suspension at this point.

Table 5 shows changes in intracellular $\mathrm{K}^{+}$ after freezing, and after washing. An average

TABLE 4

Recovery and Saline Stabiltty of Washed Celis

\begin{tabular}{c|c|c|c|c|c}
\hline & $\begin{array}{c}\text { Total Hgb } \\
\text { (mg) prior } \\
\text { to wash }\end{array}$ & $\begin{array}{c}\text { Hgb (mg) } \\
\text { recovered } \\
\text { from wash }\end{array}$ & $\begin{array}{c}\text { Recuvery } \\
\%\end{array}$ & \multicolumn{2}{|c}{$\begin{array}{c}\text { Saline } \\
\text { stability (\%) }\end{array}$} \\
\cline { 4 - 6 } & & & & Prewash & $\begin{array}{c}\text { Post- } \\
\text { wash }\end{array}$ \\
\hline 1 & 590 & 72 & 87.8 & 87 & 98 \\
2 & 630 & 76 & 87.9 & 87 & 97 \\
3 & 590 & 73 & 87.6 & 86 & 99 \\
4 & 550 & 73 & 86.7 & 86 & 96 \\
5 & 580 & 97 & 83.2 & 80 & 97 \\
6 & 605 & 110 & 81.8 & 78 & 98 \\
7 & 600 & 86 & 86.9 & 86 & 96 \\
8 & 655 & 74 & 87.7 & 88 & 99 \\
\hline
\end{tabular}

TABLE 5

Changes in Intracellular $\mathrm{K}^{+}$After Freizing With $14 \%$ HES, Thawing and Washing

\begin{tabular}{c|c|c|c|c|c}
\hline & \multicolumn{5}{|c|}{ Erythrocyte $\mathrm{K}^{+}$(meg/l) } \\
\cline { 2 - 6 } Sample & Prefreeze & $\begin{array}{c}\text { Post- } \\
\text { thaw }\end{array}$ & $\begin{array}{c}\% \text { Change } \\
\text { thest- }\end{array}$ & $\begin{array}{c}\text { Post } \\
\text { wash }\end{array}$ & $\begin{array}{c}\% \\
\text { change }\end{array}$ \\
\hline 1 & 89 & 70 & 21.4 & 65 & 27.0 \\
2 & 81 & 66 & 18.6 & 52 & 35.9 \\
3 & 93 & 80 & 14.0 & 70 & 24.8 \\
4 & 98 & 81 & 17.4 & 69 & 29.6 \\
5 & 86 & 74 & 14.0 & 67 & 22.1 \\
6 & 102 & 91 & 10.8 & 82 & 19.7 \\
7 & 84 & 73 & 13.1 & 60 & 28.6 \\
8 & 93 & 81 & 13.0 & 71 & 23.7 \\
9 & 96 & 82 & 14.6 & 74 & 23.0 \\
10 & 97 & 90 & 7.3 & 79 & 18.6 \\
$\mathrm{~N}$ & 91.9 & 78.9 & 14.4 & 68.9 & 25.3 \\
$\mathrm{SD}$ & 6.7 & 8.3 & 4.0 & 8.7 & 5.2 \\
$\mathrm{SE}$ & 2.1 & 2.6 & 1.8 & 2.8 & 1.6 \\
$11^{a}$ & 98 & 47 & 48.0 & 21 & 78.6 \\
\hline
\end{tabular}

a This sample was frozen in $8 \%$ HES.
TABLE 6

Changes in Intraceluduli ATP After Freuzing, Thawing and Washing

\begin{tabular}{|c|c|c|c|c|c|}
\hline & \multicolumn{5}{|c|}{$\mathrm{ATP} / \mu \mathrm{M} / 10^{8}$ Erythrocytes } \\
\hline & Unfrozen & Postthaw & $\begin{array}{l}\text { Post- } \\
\text { wash }\end{array}$ & $\mid \begin{array}{c}\% \text { Post- } \\
\text { thaw }\end{array}$ & $\begin{array}{c}\% \text { Post- } \\
\text { waslı }\end{array}$ \\
\hline 1 & 1.90 & 1.65 & 1.50 & 13.2 & 21.0 \\
\hline 2 & 1.77 & 1.60 & 1.52 & 9.6 & 14.0 \\
\hline 3 & 1.72 & 1.49 & 1.40 & 13.4 & 18.6 \\
\hline 4 & 1.86 & 1.70 & 1.61 & 8.6 & 13.4 \\
\hline 5 & 1.67 & 1.58 & 1.60 & 5.4 & 4.9 \\
\hline 6 & 1.93 & 1.89 & 1.74 & 2.1 & 9.8 \\
\hline 7 & 1.72 & 1.67 & 1.62 & 2.9 & 5.8 \\
\hline 8 & 1.83 & 1.71 & 1.63 & 6.6 & 10.9 \\
\hline 9 & 1.91 & 1.72 & 1.59 & 9.9 & 16.7 \\
\hline 10 & 2.03 & 1.90 & 1.79 & 6.4 & 11.8 \\
\hline $\mathrm{N}$ & 1.83 & 1.69 & 1.60 & 7.8 & 15.7 \\
\hline SD & 0.11 & 0.12 & 0.11 & 3.9 & 5.2 \\
\hline $\mathrm{SE}$ & 0.04 & 0.04 & 0.04 & 1.2 & 1.6 \\
\hline $11^{a}$ & 1.93 & 1.21 & 0.91 & 37.3 & 53.0 \\
\hline
\end{tabular}

immediate postthaw loss of $14 \%$ was observed followed by loss of another $10 \%$ after five washes in Normasol-R. The changes in erythrocyte ATP levels are shown in Table 6 . An average decrease of $8 \%$ postthaw was observed, and washing resulted in the loss of another $8 \%$. The stability of erythrocyte ATP during incubation for three hours was not significantly different in controls, thawed cells and washed cells. This data is shown in Table 7 . When $8 \%$ HES is used for freezing erythrocytes, a $48 \%$ loss of potassium was observed after thawing. The ATP levels of the same cells decreased to $13 \%$ of control. These results are shown in the last table, Table 8 .

\section{DISCUSSION}

In contrast to data presented by Meryman (11) showing an $87 \%$ loss of $\mathrm{K}^{+}$from erythrocytes frozen in $14 \%$ HES, we observed an average $15 \%$ loss of this ion immediately after freezing. Washing reduced the $\mathrm{K}^{+}$level to $70 \%$ of control values and further processing did not affect this level.

Meryman suggests that extracellular agents such as HES or PVP (12) protect erythrocytes from freeze-thaw damage by altering the membrane to allow a reversible efflux and influx of solute, thus preventing the formation of excessive osmotic gradients (11). 


\section{TABLE 7}

Effect of Three Hour Incubation upon the ATP Levels of Unfrozen, Frozen and Thawed, and Washed ERYthrocytes

\begin{tabular}{|c|c|c|c|c|c|c|c|c|c|}
\hline & \multicolumn{9}{|c|}{ ATP ( $\mu \mathrm{M} / 10^{8}$ Erythrocytes) } \\
\hline & \multicolumn{3}{|c|}{ Unfrozen } & \multicolumn{3}{|c|}{ Frozen-thawed } & \multicolumn{3}{|c|}{ Washed } \\
\hline & 0 & $3 \mathrm{Hr}$ & $\%$ Change & 0 & $3 \mathrm{Hr}$ & $\%$ Change & 0 & $3 \mathrm{Hr}$ & $\%$ Change \\
\hline 1 & 1.90 & 1.86 & & 1.65 & 1.59 & & 1.50 & 1.39 & 7.3 \\
\hline 2 & 1.77 & 1.63 & 7.9 & 1.60 & 1.58 & 1.3 & 1.52 & 1.43 & 5.9 \\
\hline 3 & 1.72 & 1.68 & 2.3 & 1.49 & 1.40 & 6.0 & 1.40 & 1.21 & 13.6 \\
\hline 4 & 1.86 & 1.77 & 1.1 & 1.70 & 1.64 & 3.5 & 1.61 & 1.52 & 5.6 \\
\hline 5 & 1.67 & 1. 61 & 3.6 & 1.58 & 1.53 & 3.2 & 1.60 & 1. 49 & 6.9 \\
\hline 6 & 1.93 & 1.88 & 2.6 & 1.89 & 1.80 & 4.7 & 1.74 & 1.65 & 5.2 \\
\hline 7 & 1.72 & 1.69 & 1.7 & 1.67 & 1.58 & 5.4 & 1.62 & 1.49 & 8.0 \\
\hline 8 & 1.83 & 1.72 & 6.0 & 1.71 & 1.62 & 5.3 & 1.63 & 1.56 & 4.3 \\
\hline 9 & 1.91 & 1.86 & 2.6 & 1.72 & 1.51 & 12.2 & 1.59 & 1.48 & 6.9 \\
\hline 10 & 2.03 & 1.99 & 1.9 & 1.90 & 1.72 & 9.5 & 1.79 & 1.66 & 7.3 \\
\hline $\mathbf{N}$ & 1.83 & 1.76 & 3.1 & 1.69 & 1.59 & 5.4 & 1.60 & 1.49 & 7.1 \\
\hline SD & 0.11 & 0.12 & 2.1 & 0.12 & 0.11 & 3.2 & 0.11 & 0.13 & 2.5 \\
\hline $\mathrm{SE}$ & 0.04 & 0.04 & 0.6 & 0.4 & 0.35 & 1.0 & 0.35 & 0.41 & 0.8 \\
\hline $11^{a}$ & 1.93 & 1.84 & 4.7 & 1.21 & 0.46 & 62.0 & 0.91 & 0.12 & 87.0 \\
\hline
\end{tabular}

"Frozen in $8 \%$ HES.

The initial $15 \%$ loss of intracellular erythrocyte $\mathrm{K}^{+}$obscrved by us corresponds to the $\mathrm{K}^{+}$ loss from glycerolized cells reported by Valeri $(17,18)$. This suggests that mechanisms other than "solute leak" may be involved in the cryoprotection of erythrocytes by HES, such as hydrogen bonding (5), and stabilization of the lattice structures (6). Both mechanisms could enhance structuring of extracellular water (10), decreasing the tendency to form hexagonal ice during rapid freezing and thawing. Another attractive mechanism would be stabilization of the cell membrane by surface deactivation somehow preventing propagation of ice crystals through the membrane (3). This merhanism has been suggested by us (16) since $14 \%$ HES prevents the unmasking of a membrane $\left(\mathrm{Ca}^{2+}+\mathrm{Mg}^{2+}\right)-$ ATPase, and damage to this structure results in activation of this enzyme with ATP loss (19). We have shown that when concentrations of $12-14 \%$ HES are used, this enzyme is not activated, but in concentrations less than $12 \%$, marked ATPase activation occurred (16).

Rinfret pointed out a correlation between the post thaw saline stability of erythrocytes preserved in the PVP, and the number of cells that would circulate upon transfusion (13). Erythrocyte survival data from our laboratory suggest an identical correlation with red cells frozen with HES. Further indications that the stability
TABLE 8

The Efrect of Freezing Erythrocytes With 8\% HES UPON $\mathrm{K}^{+}$AND ATP LeVELS

\begin{tabular}{cccc}
\multicolumn{2}{c}{$\mathrm{K}^{+}(\mathrm{meq} / \mathrm{l})$} & \multicolumn{1}{c}{ ATP $\left(\mu \mathrm{M} / 10^{\circ}\right.$ cells $)$} \\
\hline Prefreeze & Postthaw & Prefreeze & Posthaw \\
\hline 101 & 49 & 2.02 & 0.23 \\
91 & 47 & 1.96 & 0.21 \\
98 & 46 & 1.87 & 0.20 \\
101 & 53 & 1.99 & 0.25 \\
\hline
\end{tabular}

of thawed cells in saline measure in vivo recovery are seen in the fact that the saline stability test predicted the percentage of cells lost during the washing procedures.

The development of a process utilizing hydroxyethyl starch, modified by the manufacturer at our suggestion, to provide an acceptable extracellular cryoprotective agent was initiated to make available erythrocytes that could be administered without postthaw process. However, the high visensity of the HF.S-parked rell mixture limits large volume use of blood without first processing to remove a portion of the HES. The results reported in this paper suggest that hydroxyethyl starch can be effectively removed from red cells by washing in a balanced salt solution.

Normasol-R was chosen as a preliminary 
washing agent since it is an approved parenteral solution. This is not an ideal solution for use in existing automated blood washing units since these systems require initial high density wash solutions such as 15 or $20 \%$ mannitol, but results obtained using the balanced salt solution demonstrate that HES can be washed out of the packed cells thus effectively lowering the viscosity. Other systems must be explored with particular emphasis on further reducing loss of intracellular $\mathrm{K}^{+}$. Since HES is nontoxic and nonantigenic (9), and has not in our hands shown any adverse affects upon coagulation, it may be only necessary to partially remove it from the cells to obtain the required viscosity for rapid transfusion.

\section{SUMMARY}

Packed human erythrocytes were frozen in liquid nitrogen using hydroxyethyl starch as a cryoprotective agent. Upon thawing, the cells were washed with a balanced salt solution. The washed cells were stable when resuspended in $0.154 \mathrm{~N} \mathrm{NaCl}$. The postthaw saline stability approximated the total recovery after washing the cells. Intracellular potassium loss was $15 \%$ immediately postthaw, and an additional $15 \%$ loss occurred after washing. These results indicate that HES can be removed from frozen-thawed cells by washing, and that freezing erythrocytes protected by HES does not result in significant losses of intracellular potassium.

\section{REFERENCES}

1. Beutler, E., and Baluda, M. D. Simplified determination of blood adenosine triphosphate using the firefly system. Blood 23, 688-698 (1964).

2. Boutwell, J. H.: Sodium and Polassium. In "Clinical Chemistry Laboratory Manual and Methods" (J. H. Boutwell, eLa and Febiger, pp. 248-252, Philadelphia, 1961.

3. DeVries, A. L. Glycoproteins as biological antifreeze agents in Antarctic fishes. Science 172, 1152-1155 (1971).

4. Doebbler, G. F., Dwyer, R. F., and Rinfret, A. P. A simple comparative method of measuring red cell viability. Nature (London) 195, 912-913 (1962).

5. Doebbler, G. F., and Rinfret, H. P. The influence of protective compounds and cooling and warming conditions on hemolysis of erythrocytes by freezing and thawing. Biochim. Biophys. Acta. 58, 449-458 (1962).
6. Karow, A. M., Jr., and Webb, W. R. Tissue freezing: A theory for injury and survival. Cryobiology 2, 99-108 (1965).

7. Kesler, C. C., and Hjermstad, E. T. In "Methods in Carbohydrate Chemistry" (Edd) Royal Whistler, pp. 304-306. Academic Press, New York, 1964.

8. Knorpp, C. T., Merchant, W. R., Gikas, P. W., Spencer, H. H., and Thompson, N. W. Hydroxyethyl starch: extracellular cryophylactic agent for erythrocytes. Science 157, 1312-1313 (1967).

9. Maurer, E. H. Immunologic Studies with hydroxyethyl starch (HES) a proposed plasma expander. T'ransfusion 8, 265-268 (1968).

10. Mazur, P. Cryobiology: The freezing of biological systems. Science 168, 939-949 (1970).

11. Meryman, H. T. Cryoprotective agents. Cryobiology 8, 173-183 (1971).

12. Richards, V., Braverman, M., Floridia, R., Persidsky, M., and Lowenstein, J. Initial clinical experiences wilh liquid nilrogen preserved blood, employing PVP as a protective additive. Amer. J. Surg. 108, 313-322 (1964).

13. Rinfret, A. P. Some aspects of preservation of blood by rapid freeze thaw procedures. Fed. Proc. 22, 94-101 (1963).

14. Robson, D. C. Rapid Freezing and Thawing Techniques Using Extracellular Agents, In "Modern Problems of Blood Preservation." (Ed) Gustav Fisher pp. 204-208. Verlag, Stuttgart, 1970.

15. Schinowara, G. Y. Spectrophotometric studies of blood serum and plasma. The physical determination of hemoglobin and bilirubin. Amer. J. Clin. Pathol. 24, 696-707 (1954).

16. Starkweather, W. H., Knorpp, C. T., and Spencer, H. H. The preservation of erythrocyte membrane enzymes at low temperatures with hydroxyethyl starch (HES). In "XII International Congress of Hematology," Abstract Volume, p. 18. Munich, Germany, 1970.

17. Valeri, C. R., and Hirsch, N. M. Restoration in-vivo of erythrocyte adenosine triphosphate, 2,3-diphosphoglycerate, potassium ion, and sodium ion concentrations following the transfusion of acid-citrate-dextroscstarch human red blood cells. J. Lab. Clin. Med. 73, 722-733 (1969).

18. Valeri, C. R., and Runck, A. H. Viability of glycerolized red blood cells frozen in liquid nitrogen. Transfusion 9, 306-313 (1969).

19. Wins, P., and Schoffeniels, E. A "latent" dinitrophenol-stimulated ATPase in red cell ghosts. Biochem. Biophys. Acta. 135, 831 1967). 